\title{
The Best of Both Worlds: How Rural Entrepreneurs Use Placial Embeddedness and Strategic Networks to Create Opportunities
}

\author{
Steffen Korsgaard \\ Department of Management, Aarhus University, Denmark \\ Bartholins Alle 10 \\ DK-8000 Aarhus C \\ \& \\ Center for Entrepreneurship \\ University of Oslo \\ E-mail: stk@asb.dk \\ Richard Ferguson \\ Swedish University of Agricultural Sciences \\ Johan Brauners $v 3$ \\ SE-750 07 Uppsala \\ Johan Gaddefors \\ Swedish University of Agricultural Sciences \\ Johan Brauners v 3 \\ SE-750 07 Uppsala
}

This is an Accepted Manuscript of an article to be published by Taylor \& Francis Group in Entrepreneurship and Regional Development, available online:

http://dx.doi.org/10.1080/08985626.2015.1085100 .

This research was supported by a research grant from the Danish Business Authority and the European Social Fund 


\title{
The Best of Both Worlds: How Rural Entrepreneurs Use Placial Embeddedness and Strategic Networks to Create Opportunities
}

\author{
Entrepreneurial activities are strongly influenced by the context in which they occur. It is \\ therefore imperative to understand how different contexts enable entrepreneurs to create \\ opportunities. In this paper we focus on the spatial context of rural entrepreneurs and explore \\ how the rural context impacts on their opportunity creation. Based on a multiple case study we \\ find that rural entrepreneurs mix what we refer to as placial embeddedness - an intimate \\ knowledge of and concern for the place - with strategically built non-local networks, i.e. the \\ best of two worlds. Notably, the entrepreneurs seek to exhaust the localised resource base \\ before seeking out non-local resources. Our findings thus contribute to our understanding of \\ entrepreneurship in context and challenge future research to explore how different forms of \\ contexts are bridged in different settings to create varieties of entrepreneurial activities.
}

Keywords: context; embeddedness; rural entrepreneurship; space; place; opportunity creation; networks

\section{Introduction}

Entrepreneurship is a vital mechanism in creating economic activity and growth in rural settings. It is therefore important to understand the circumstances that enable and constrain entrepreneurial activity in rural areas (Labrianidis 2006, Stathopoulou, Psaltopolous, and Skuras 2004): How does the rural context influence the kinds, processes, and outcomes of entrepreneurial activities that are or could be - undertaken? This practical question is well reflected in the increasing attention academics in the entrepreneurship field are giving to contextual issues and how different forms of context influence entrepreneurial processes (Lang, Fink, and Kibler 2014, Thornton 1999, Welter 2011, Zahra 2007).

Several streams of research into entrepreneurship have identified contextual phenomena, including embeddedness, where an actor's contextual ties facilitate access to contextually bound resources; and bridging, where actors establish ties outside of a particular context, opening access to 
new resources. Studies of entrepreneurs in rural and/or depleted areas have shown how engagement in social networks and communities gives entrepreneurs access to local resources, and also how communities, in turn, will rally around and support entrepreneurial ventures to the benefit of the local areas (Anderson 2000, Jack and Anderson 2002, McKeever, Anderson, and Jack 2014, McKeever, Jack, and Anderson 2015).

This interaction resonates with the general theories of networks, institutions, and entrepreneurship, which propose that contexts can provide entrepreneurs with information about useful opportunities as well as access to resources needed to pursue them (Burt 2000, Burt 2004, Johannisson 1988, Ruef 2002, Thornton 1999, Klyver and Hindle 2007). Extending this proposition, it is also suggested that by bridging across otherwise unconnected social and institutional contexts, entrepreneurs can access additional resources to build and grow their ventures (Yang 2004, Burt 2000, Burt 2004).

Most of the research into the role of context and embeddedness has focused on social networks and institutional contexts, with little attention given to the spatial context (Welter 2011, Hindle 2010). While social networks and institutional contexts are surely extremely important, a comprehensive understanding of the role of context in rural entrepreneurship must also address spatial context. The spatial context is here defined as the topographical, geographical, and infrastructural elements as well as the meanings, experiences, and heritage of the location(s) of the entrepreneurial opportunity creation process. Also the movement and bridging between different spatial contexts may be of importance here, as entrepreneurship often involves interaction in globalised flows of products, capital, and people, which connect and constitute locations (Castells 1999, Korsgaard, Müller, and Tanvig 2015). In this study we therefore explore i) how spatial context influences entrepreneurial opportunity creation, and ii) how entrepreneurial opportunity creation bridges spatial contexts? The study gives insight into the role of spatial context in 
particular, and shed light on how entrepreneurs bridge not simply across social networks and institutions - as emphasised in most extant research - but also across different dimensions of context, connecting local and non-local contexts.

In the research reported here, we take a qualitative case-study approach (Yin 2009, Eisenhardt 1989), investigating seven cases situated on small, rural Danish islands. The in-depth qualitative research design allows us to investigate the phenomenon in its real-life context (Yin 2009), build detailed narratives displaying the process (Flyvbjerg 2004), and allowing account to be taken of the blurred boundaries of concepts as well as empirical settings (Yin 2009).

In our analysis three thematic codes stand out as particularly prominent: the local spatial context, the local social context, and the non-local social context. From the coding of the local spatial context we develop the concept of placial embeddedness to denote the entrepreneur's knowledge and use of the physical, cultural, and historical landscapes on their respective islands, as well as the entrepreneur's strong concern for the wellbeing of the local island communities.

Our study furthermore reveals a surprising balance between the use of local and non-local social contexts. The investigated entrepreneurs made much less use of local networks than expected; while the non-local networks were frequently used for strategic purposes such as finance, marketing, knowledge, and advice. Most notably, however, these non-local network contacts were established by the entrepreneurs to address specific business-related needs, and they were created after moving to the island. The entrepreneurs did not leverage their prior connections (exploiting their non-local social context), as would be expected from existing theorising. A distinct pattern can be seen in our data, where the entrepreneurs are actively seeking the best of two worlds, first by exploring and developing the use of locally-bounded resources, and then by reaching beyond the local context to secure locally-deficient but strategically vital business resources in non-local specialised networks. 
The results challenge existing theory in several ways. The bridging illustrated by our cases was far from the opportunistic leveraging of knowledge flows emphasised in previous literature (see e.g. Burt 2000, 2004). Rather than exploiting a parallel embeddedness in multiple networks to bridge across structural holes, we saw how rural entrepreneurs enacted opportunities in local places. The central enabling bridging is not - as suggested by Burt $(2000,2004)$ - across social network contexts, but rather between a local place and a non-local social context of new strategically-formed partnerships. Direct exchanges with local social networks were less important to the entrepreneurial activities than suggested by existing research (Burt 2004, Kloosterman, Van Der Leun, and Rath 1999, Kloosterman 2010); with our cases instead deriving value from the knowledge and experience of the local material, and the historical and cultural place in the rural opportunity creation process.

In the next section we present the theoretical background followed by the methods used, our findings, and a discussion. To conclude the article we discuss limitations before we sum up our contribution.

\section{Theoretical background}

\subsection{Context and entrepreneurship}

It is well established both theoretically and empirically that entrepreneurial activities are embedded in contexts and that this has a significant impact on the economic activities and performance of both individuals and organisations (Dacin, Ventresca, and Beal 1999, Thornton 1999). Being embedded is defined here as being situated in a context which enables and constrains the activities of actors. From this perspective entrepreneurial processes are contextualised (Thornton 1999, Zahra 2007) and will unfold differently across contexts (Welter and Smallbone 2011). Following recent calls for more contextualised studies of entrepreneurship (Welter 2011, Trettin and Welter 2011, Zahra 2007, Steyaert and Katz 2004, Korsgaard, Müller, and Tanvig 2015), the social and institutional 
contexts have received some attention, also in the study of entrepreneurship in rural and depleted areas.

\subsubsection{Social and institutional context}

Sociological theories suggest that economic activities such as entrepreneurship are embedded in social network contexts consisting of interpersonal relationships (ties) that can enhance an entrepreneur's ability to succeed by e.g. gaining access to idiosyncratic information, access to resources on favourable terms, and provide much needed legitimacy to the entrepreneur (cf. Thornton 1999, Burt 2000, Burt 2004, Gnyawali and Madhavan 2001, Baum, Calabrese, and Silverman 2000). Much of the existing research in the entrepreneurship field follows this line of thinking of emphasising the enabling role of social contexts in entrepreneurial activity (Elfring and Hulsink 2003, Granovetter 1973, Hite and Hesterly 2001, Jack 2005, Klyver and Hindle 2007).

Several studies have shown this enabling effect to be pronounced in rural and depleted areas (Jack and Anderson 2002, McKeever, Anderson, and Jack 2014). In a seminal study of entrepreneurs' social embeddedness in a rural context Jack and Anderson (2002) showed how local social ties become a competitive advantage for rural entrepreneurs by providing a source of opportunities and allowing access to resources otherwise not available. Entrepreneurial activity is thus fundamentally "conditioned by the dynamics of the entrepreneur and the social structure" (Jack and Anderson 2002: 468). Notably, the studies of the enabling force of social embeddedness have also suggested that it may be possible for an entrepreneur to be too embedded, and that social networks, perhaps particularly in rural areas, may stifle entrepreneurial activities e.g. by enforcing strict social norms and enforce conformity to local values (Jack and Anderson 2002, see also Schnell and Sofer 2002, Klyver, Evald, and Hindle 2011).

A distinct theme in some of the research on the enabling role of social network contexts emphasises the advantage of being able to bridge across multiple contexts. The original sociological 
work suggests that entrepreneurs can benefit from bridging across otherwise disconnected networks, acting as a form of broker (Burt 2000, Burt 2004). "People with connections across structural holes have early access to diverse, often contradictory, information and interpretations, giving them a competitive advantage in seeing and developing good ideas" (Burt 2004: 388). The advantage provided by being embedded in multiple contexts or networks has been used to explain the overrepresentation in numbers and better overall economic performance of in-migrant entrepreneurs in rural areas (Kloosterman, Van Der Leun, and Rath 1999, Kloosterman 2010, Kalantaridis and Bika 2006). In-migrant entrepreneurs are embedded both in the local context and local networks as well as non-local contexts and networks. The rationale being that the in-migrant entrepreneurs are somehow able to leverage this mix in various ways that enable start up and subsequent performance. Kloosterman (2010) notes that the success of an entrepreneurial endeavour is largely contingent upon access to required resources and access to the market in which an opportunity has been detected. Kloosterman (2010) further asserts that in-migrant entrepreneurs can have an advantage in being embedded in both local networks and in a non-local ethnic group. Marti and colleagues (2013) identified a similar bridging mechanism in play at the community level where "known strangers" bridging the boundaries between a local impoverished community and outside resources enabled community development that would have been impossible through the agency of the locals alone.

The issue of context has also been explored from an institutional perspective emphasising the "economic, political, and cultural environment in which the entrepreneur operates" (Welter and Smallbone 2011: 107). The relations between institutional contexts and entrepreneurial action, however, are quite complex. On the one hand strong and stable institutions reduce uncertainty and risk for entrepreneurs, while on the other hand lacking or deficient institutions provide both need and opportunity for entrepreneurs to create opportunities (see Mair and Marti 2009, Williams and 
Vorley 2015 for studies pointing in either direction). A recent study adopting an institutional approach to place, focuses on the diversity of local institutions and values in rural Central Europe, and how they influence entrepreneurial activities (Lang, Fink, and Kibler 2014). This study found extraordinary differences across local places and also showed how the alignment of the regulative, normative, and cognitive elements of the institutional context is important for the enhancement of entrepreneurial activity.

Similar to networks, institutions can also serve as a source of information, resources, and legitimacy (see e.g. Cleaver 2001). Entrepreneurial activities may thus be influenced by the resources at large ingrained in the institutions in which the entrepreneur is embedded. Consequently, bridging across institutional contexts may also be a source of opportunity for entrepreneurs. This is clearly shown in the case study by Yang (2004), where institutions controlled potentially complementary resources for entrepreneurial ventures which entrepreneurs could leverage when they bridged across institutions.

The study of the social and institutional contexts of entrepreneurship has enhanced our general understanding of the heterogeneity of entrepreneurial responses to external conditions, as well as demonstrated how structural factors influence entrepreneurial processes at the micro-level (cf. Welter and Smallbone 2011, Thornton 1999, Welter 2011). Such studies thus constitute a vital element for entrepreneurship theorising (Zahra 2007), by making the theorising sensitive, in several ways, to the social and institutional contexts in which entrepreneurship occurs (Welter 2011). Firstly, this has in particular helped researchers explore on the one hand how economic rationality and optimisation is often compromised by social and institutional embeddedness and on the other hand how this enables entrepreneurial activities for individuals with privileged positions in networks and institutions. Secondly, it has demonstrated the importance of bridging activities in enabling entrepreneurial activity, be it bridging across social or institutional boundaries. 


\subsubsection{Spatial context}

The explorations of social and institutional contexts do not exhaust the story of how context influences entrepreneurial processes. Indeed, as suggested in several recent reviews, the role of the spatial context, especially at the localised level, has been much less researched (for exceptions see Anderson 2000, Hjorth 2004, Johnstone and Lionais 2004), and warrants a deeper exploration (Trettin and Welter 2011, Welter 2011, Lang, Fink, and Kibler 2014, Müller 2013, Korsgaard, Müller, and Tanvig 2015).

The dearth of research on the role of the local spatial context is particularly precarious in relation to rural entrepreneurship on conceptual as well as practical level. At the practical level, studies of the spatial context of rural entrepreneurship can help to identify and disseminate ways in which entrepreneurs in resource-scarce rural areas can optimise the use of localised (spatial) resource bases and generally overcome the liabilities of residing in peripheral areas (cf. Kitchen and Marsden 2009).

At the conceptual level, rural entrepreneurship is a spatial definition, which suggests that it is (partly) the spatial characteristics that set rural entrepreneurship apart from other forms of entrepreneurship (cf. Korsgaard, Müller, and Tanvig 2015, Kalantaridis and Bika 2006). Accordingly, a comprehensive understanding of rural entrepreneurship involves a deep consideration of how entrepreneurs' embeddedness in spatial contexts as well as their bridging across local and non-local contexts enables entrepreneurial activities.

The spatial context refers to the socio-material locality in which the entrepreneurial process takes place. In other words the intersection of topographical, geographical, environmental, and infrastructural materiality and the socialised meanings and experiences attached to these materialities (cf. Hudson 2001, Cresswell 2006, Tuan 2007/1977, Castells 1999, Korsgaard, Müller, and Tanvig 2015). Extant research on place and entrepreneurship has tended to focus on the 
socialised aspect of place at the expense of the material elements (see e.g. Johnstone and Lionais 2004, Lang, Fink, and Kibler 2014, McKeever, Jack, and Anderson 2015).

In the studies of entrepreneurship and the rural spatial context that exist, the distinction between space and place has often been invoked (Johnstone and Lionais 2004, Müller 2013, Korsgaard, Müller, and Tanvig 2015). Space and place denotes two different aspects of spatial contexts and two perspectives from which it is possible to explore a given spatial context for entrepreneurial activities (Tuan 2007/1977, Cresswell 2006). Following Hudson (2001) and Johnstone \& Lionais (2004), space denotes “an economic (capitalistic) evaluation of location based on its capacity for profit" (Johnstone and Lionais 2004: 218). Space is thus related to the movement and flow of capital, labour, resources, and information, and dominated by economic concerns relating to the optimisation of profit or accumulation of economic value for companies, countries, and regions (Castells 1999, Hudson 2001). Space may thus enable and constrain entrepreneurial activity through the availability of e.g. human, social, and financial capital, infrastructural linkages (or lack thereof) to other spaces and access to certain types of resources or factors for production.

Place on the other hand, denotes an evaluation of a location in relation to lived life and experience (Johnstone and Lionais 2004, Tuan 2007/1977, Hudson 2001). A location becomes a place if meanings and experiences are attached to it. We can therefore define "place" as a set of material and social practices that enact a location (Hudson 2001, Cresswell 2006, Tuan 2007/1977). Very limited research exists on the role of place in entrepreneurial activities, but it may be speculated that experiential and meaning-related dimensions such as culture, heritage, and history may in some cases enable entrepreneurial opportunity creation (Neergaard, Korsgaard, and Hindle 2008, Müller 2013).

The distinction between space and place suggests that the immediate local context of entrepreneurial activities can have economic as well as socialised, experiential, material etc. 
dimensions, and that these dimensions may enable and constrain entrepreneurial activities in different ways. Indeed, it may be argued that rural spatial contexts offer distinct, yet, complex circumstances for entrepreneurial activities, with significant impact on the processes and outcomes of rural entrepreneurship (cf. Johnstone and Lionais 2004, Anderson 2000, Kitchen and Marsden 2009).

\subsection{Entrepreneurship and the rural}

Regardless of how you define rural (Hoggart 1990), it is commonly accepted that rural areas face significant challenges in most developed countries. In general, rural areas experience the dark side of the unequal regional developments that characterise late modern society. This manifests itself in an overall inferior economic performance of rural areas (OECD 2006), associated with factors such as ageing population, out-migration, lower labour productivity, lower educational levels, and a lower level of public services (OECD 2006).

Entrepreneurship is broadly perceived as a key mechanism to counteract the problematic developments of rural areas (North and Smallbone 2006, OECD 2006, Labrianidis 2006). And indeed rural areas are sites of diverse and fascinating entrepreneurial activities both within traditional farming-based activities (Carter 1998, Alsos, Carter, and Ljunggren 2014, Ferguson and Olofsson 2011) and non-traditional industries such as tourism, experience, production, and information technology (Tanvig 2012, Gaddefors and Cronsell 2009). Yet, rural entrepreneurs, in addition to universal liabilities of newness and smallness, face particular challenges related to the spatial setting (OECD 2006). Rural areas typically have lower levels of financial and human capital in addition to the infrastructural challenges of being located away from urban hubs of economic activity (OECD 2006). On the upside, scholars have suggested that rural areas offer distinct 
advantages in terms of lower land prices, loyal and stable work force and natural amenities (JensenButler 1992, Kalantaridis and Bika 2006).

At an overall level, rural areas show inferior entrepreneurial activities compared to urban areas (OECD 2006), indicating that there may be significant potential in most rural areas for more value-creating entrepreneurial activities that can improve the overall economic performance and quality of life in rural areas. At the same time, opportunities do not necessarily present themselves in abundance in rural areas. They may need to be created. Here we define opportunities as situations in which new ends-means combinations can be introduced and sold in a market (Shane and Venkataraman 2000, Korsgaard 2011). In this definition it is neither assumed nor precluded that the opportunity pre-exists the entrepreneurial activities. While it is possible that the entrepreneurial activities address a pre-existing price discrepancy in the market (Shane and Venkataraman 2000), we do focus on the creative work of the entrepreneur(s) and other stakeholders to bring about the situation in which new ends-means combinations can be introduced (cf. Sarasvathy 2001, Korsgaard 2013). Therefore, we do also not assume that the opportunities are necessarily profitable for the entrepreneurs.

\subsection{Purpose and research questions}

Based on the above, we address two central research gaps: Firstly, there is a need for a deeper understanding of the role of spatial context in entrepreneurial processes (cf. Trettin and Welter 2011, Welter 2011, Hindle 2010), in particular in relation to rural entrepreneurship, as spatial dimensions present both particular challenges and possibilities for rural entrepreneurs. Secondly, there is a need to understand how rural entrepreneurs bridge beyond the local context in the creation of entrepreneurial opportunities. Prior studies suggest that these two issues interlink insofar as entrepreneurs do not simply bridge structural holes in networks, but become closely embedded in and actively seek to change spatial and institutional dimensions of their new locations (Gaddefors 
and Cronsell 2009, McKeever, Jack, and Anderson 2015, Müller 2013). The purpose of this study is thus, as stated above, to explore the following two research questions: i) how spatial context influences entrepreneurial opportunity creation, and ii) how entrepreneurial opportunity creation bridges spatial contexts? In addressing these questions we seek to add to our understanding of rural entrepreneurship as well as the role of spatial context for entrepreneurial processes.

\section{Methods}

A multiple case-study research strategy is deployed in this study (Yin 2009, Eisenhardt 1989). Several scholars have pointed to the expedience and need for qualitative studies of localised entrepreneurial processes in order to gain a deeper understanding of the role of context and bridging for entrepreneurial activity (Trettin and Welter 2011, Welter 2011, Hindle 2010). As indicated above, the issue of context has hitherto been studied primarily with a focus and emphasis on embeddedness in social networks and institutions. Established quantitative methods exist for the study of structures and content of networks; however, this is not the case for spatial context, as the study of places involves engagement with complex meanings and qualities attached to locations, which are not easily quantified (Tuan 2007/1977). Furthermore, limited knowledge exists of the rural spatial context and consequently no established and precisely-defined concepts and constructs exist for measuring the interaction between entrepreneurial activities and spatial rural context. This necessitates an in-depth qualitative research design that allows researchers to investigate the phenomenon in its real-life context (Yin 2009).

The limited knowledge and conceptualisation of the phenomenon of spatial context in rural entrepreneurship necessitates theory development. Eisenhardt (1989) points to multiple case studies as a solid research strategy for theory development. The depth and closeness to the phenomenon and context and the iterative analysis work create models and concepts that are validated in concrete 
observations and data (Eisenhardt 1989), building theories that do not depend on abstract speculation.

\subsection{Case selection}

For the purpose of exploring the role of the spatial context and the bridging to and from the local context in resource-scarce rural areas, we decided to study cases on small rural islands in the national setting of the primary researcher (Denmark). Rural island ventures can be said to constitute critical or extreme cases where both the enabling and constraining forces of spatial context can be expected to be clearly visible. The island setting has the advantage of allowing for a very clear distinction between the local and non-local, as the coastlines are clear physical, social, and experiential boundaries. This boundary between the local and non-local makes it easier to identify effects and workings of context and bridging in the cases used in the present study compared to less clearly demarcated rural areas on the mainland.

Furthermore, rural island entrepreneurs face just about the most extreme infrastructural and resource-scarce challenges possible in the Danish setting. Indeed, rural island settings represent an intensification of some of the challenges that rural entrepreneurs face in general (Baldacchino 2005). This includes shortage of resources in the sense that rural island settings offer relatively poorer access to human, financial ${ }^{1}$ and social forms of capital. Furthermore, local markets are typically small (the ventures studied were all located on small islands with a population ranging from 35 to 850). Finally, as these rural islands depend on transportation by sea, the transaction costs of acquiring resources from and selling to non-local markets are significantly higher than for rural ventures located on the mainland.

\footnotetext{
${ }^{1}$ The limited access to financing is partly mediated by the existence of various public programs to support entrepreneurial activities in rural as well as rural island settings.
} 
The cases were selected through expert sampling (Neergaard 2007), where we relied on an expert intimately familiar with the unique settings of Danish rural islands and the ventures, which are located in this setting. The expert-sampling strategy is well suited for the type of study conducted here. As the overall population of rural island ventures in Denmark is relatively small, there is limited point in seeking representativeness in the cases. On the contrary, the multiple casestudy approach relies on the use of information-rich and intrinsically-interesting cases (Stake 2000, 1995). Such cases are hard to find without the use of knowledgeable individuals familiar with the setting and population. As such, we solicited the assistance of a coordinator in a network for small rural island ventures to identify interesting cases for us. As it happened, all the cases identified by the expert were in-migrants, which allowed us to explore the possible workings of bridging in all the cases. Table 1 presents the cases.

As the cases were identified with the help of an expert, it is essential that the cases vary on important dimension including size and location, as well as the gender, industry experience, family status etc. of the entrepreneurs. Such variety enhances the robustness of the findings through a literal replication logic (Yin 2009).

Table 1. Summary of the cases 


\begin{tabular}{|c|c|c|c|}
\hline $\begin{array}{l}\text { The venture and } \\
\text { location }\end{array}$ & Product & Annual turnover & The entrepreneur \\
\hline $\begin{array}{l}\text { Avernakø Geder } \\
\text { (Avernakø goats), } \\
\text { Island of Avernakø, } \\
100 \text { inhabitants }\end{array}$ & $\begin{array}{l}\text { Production of goat meat and } \\
\text { other products made from } \\
\text { goats. Catering. Starting a } \\
\text { B\&B at the old school on the } \\
\text { island }\end{array}$ & $\begin{array}{l}>1 \text { mio DKK } \\
\text { Approx. } 135,000 \\
\text { Euro }\end{array}$ & $\begin{array}{l}\text { Gitte } \\
\text { Trained nurse }\end{array}$ \\
\hline $\begin{array}{l}\text { Fur Bryghus } \\
\text { (Fur Brewpub), } \\
\text { Island of Fur, } 850 \\
\text { inhabitants }\end{array}$ & Brewery with a restaurant & $\begin{array}{l}<10 \text { mio DKK } \\
\text { Approx. } 1,320,000 \\
\text { Euro }\end{array}$ & $\begin{array}{l}\text { Mogens }^{2} \\
\text { At the time of startup CEO of a } \\
\text { large local firm }\end{array}$ \\
\hline $\begin{array}{l}\text { Klode Gårdbutik } \\
\text { (Klode farmshop) } \\
\text { Island of Fur, } 850 \\
\text { inhabitants }\end{array}$ & $\begin{array}{l}\text { Farm shop selling meat from } \\
\text { the farm and other items }\end{array}$ & $\begin{array}{l}>1 \text { mio DKK } \\
\text { Approx. } 135,000 \\
\text { Euro }\end{array}$ & $\begin{array}{l}\text { Lisbeth and Thomas (married). } \\
\text { Lisbeth is the entrepreneur of the } \\
\text { two and a trained psychologist }\end{array}$ \\
\hline $\begin{array}{l}\text { Skarø Is } \\
\text { (Skarø ice cream), } \\
\text { Island of Skarø, } 35 \\
\text { inhabitants }\end{array}$ & $\begin{array}{l}\text { Production of ice cream and } \\
\text { running a small café during } \\
\text { the summer }\end{array}$ & $\begin{array}{l}>1 \text { mio DKK } \\
\text { Approx. } 135,000 \\
\text { Euro }\end{array}$ & Britta and Martin (married) \\
\hline $\begin{array}{l}\text { Strynø Frugthave } \\
\text { (Strynø orchard), } \\
\text { Island of Strynø, } 200 \\
\text { inhabitants }\end{array}$ & $\begin{array}{l}\text { Production of high-end } \\
\text { juices made from apples } \\
\text { from Mette's own orchard }\end{array}$ & $\begin{array}{l}>1 \text { mio DKK } \\
\text { Approx. } 135,000 \\
\text { Euro }\end{array}$ & $\begin{array}{l}\text { Mette } \\
\text { Formerly consultant and trained } \\
\text { gardener }\end{array}$ \\
\hline $\begin{array}{l}\text { Øhavets madhaindvork } \\
\text { (Craft foods of the } \\
\text { Archipelagoes), } \\
\text { Island of Strynø, } 200 \\
\text { inhabitants }\end{array}$ & $\begin{array}{l}\text { Jam production using local } \\
\text { recipes and berries }\end{array}$ & $\begin{array}{l}>1 \text { mio DKK } \\
\text { Approx. } 135,000 \\
\text { Euro }\end{array}$ & $\begin{array}{l}\text { John } \\
\text { Formerly a sail ship captain }\end{array}$ \\
\hline $\begin{array}{l}\text { Arø Vingård } \\
\text { (Arø vineyard), } \\
\text { Island of Arø, } 200 \\
\text { inhabitants }\end{array}$ & $\begin{array}{l}\text { Small vineyard. Including } \\
\text { tours and events at the } \\
\text { vineyard }\end{array}$ & $\begin{array}{l}650,000 \mathrm{DKK} \\
\text { Approx. } 87,000 \\
\text { Euro }\end{array}$ & $\begin{array}{l}\text { Sven Åge } \\
\text { Formerly CEO in the construction } \\
\text { industry }\end{array}$ \\
\hline
\end{tabular}

All the ventures are relatively small and could easily be classified as small businesses with the exception of Fur Bryghus, which is a bigger venture than the rest and also distinguishes itself by pursuing a growth strategy. Notably, however, on the issues studied here, Fur Bryghus showed no significant differences from the other ventures. Furthermore, the focus of this study is on the opportunity creation process of the entrepreneur, focusing on the entrepreneurial mobilisation and

${ }^{2}$ At the time of the data collection, Mogens had unfortunately passed away. Interview data for this case thus consists of an interview with current CEO of the venture, Per. The ideas and experiences of the original founder Mogens are fortunately related in a number of newspaper articles about the brewery and its start up. These were included in the study and triangulated with the interview data from Per to validate the data. 
combination of resources in the early stages of the venture, and not the subsequent management strategies and routines of the venture as a small business.

\subsection{Data collection}

The primary data source for the study was qualitative interviews with the founder(s) (or in the case of Fur Bryghus the current CEO). The qualitative interviews were conducted on-site in the rural island settings allowing the researchers to experience the setting and gain insight into the everyday activities of the entrepreneurs. For the interviews a semi-structured approach was used to ensure an elaborate narrative as well as coverage of central issues related to the entrepreneurial activity and its context.

Additional document data was gathered from media coverage and internet sources of the ventures. Despite their small size, all the ventures had received significant media coverage, probably at least partly on account of the location on rural islands. In the analysis this proved very helpful as it allowed for the validation of the critical events and their temporal ordering through data triangulation of interview data and secondary media data (Miles and Huberman 1994).

\subsection{Data analysis}

The data was coded in accordance with established practices for qualitative theory building in which analysis of the individual cases is combined with cross-case comparisons seeking to identify patterns of similarity and difference (Miles and Huberman 1994, Strauss and Corbin 1990). The analysis of cases is combined with recursive involvement of existing literature to refine themes and relations found in the data. Following Miles and Huberman (1994), the analytic process was initiated with the design of a preliminary conceptual framework helping to focus the empirical data collection and analysis. The conceptual framework identifies themes that were included in the semistructured interview as well as thematic codes for data analysis (Miles and Huberman 1994). Initial 
focus was devoted to spatial context, supplemented with social and institutional context, to allow for an exploration of how these different forms of contexts are interrelated. Also, given the focus on spatial context, a distinction was made between the local and non-local in the thematic coding. This conceptual framework allows us to explore the entrepreneurs' embeddedness in contexts and the bridging to and from the local context. The preliminary conceptual framework proved a useful tool for directing and focusing analysis of the data. Yet, we emphasise that the purpose of the study was not to confirm or disconfirm the framework (cf. Yin 2009, Eisenhardt 1989, Miles and Huberman 1994).

Building on our preliminary conceptual framework, the analytic process proceeded with thematic coding of the data (Miles and Huberman 1994). This coding established the relevant thematic codes and event codes for each case and served as foundation for cross-case comparison. The thematic coding initially deployed the conceptual framework, yet allowed for the creation of new concepts as well as elaboration of the existing concepts. As an example the concept of placial embeddedness was developed from data coded in the thematic code on local spatial context. This part of the process was conducted using the NVivo 10 software. In addition to the thematic coding, event structure tables were created for each case allowing us to explore the temporal ordering of the key events for each case, such as moving to the island, starting the new ventures, and forming strategic partnerships (Miles and Huberman 1994). It further allowed us to compare the sequencing of key events across cases.

\section{Findings}

In the following the findings are presented. Initially, some descriptive findings are presented that give an overview of patterns in the data, including the overall prevalence of thematic codes and a general event sequence structure for the cases. Subsequent sections explore the "how" (cf. Yin 2009) research questions related to the spatial and social contexts and bridging, by exploring in 
depth the concepts of placial embeddedness, non-local strategic networks, local social embeddedness, and opportunity creation. Finally, section 4.6 discusses the "why" (cf. Yin 2009) question related to the pattern of combining placial embeddedness and non-local strategic networks; i.e. the best of two worlds.

\subsection{Descriptive findings}

In the initial thematic coding three thematic codes emerged as particularly important: local spatial context, non-local social context, and local social context. Local spatial context and non-local social context were recurring themes with significant importance across the cases, however, as will be seen below, in ways that extend and challenge how these issues are dealt with in the existing literature. Local social context was also interesting, primarily because it was less pronounced and leveraged in different ways than expected, based on the existing literature. It was surprising that non-local social context appears to be more important and prevalent than the local variant.

The qualitative interpretation that the above three thematic codes were important was supported by the distribution and prevalence of these codes in the coding as shown in table 2 which provides an overview of the initial thematic codes and their occurrence in the data. The table indicates that the codes for local spatial context and non-local social context are prevalent in the data, and local social context comparably less so. The table also breaks down the codes into interview data and document data for triangulation purposes. The similarity in the distribution between interview and document data suggests that the findings are not solely an effect of the focus of the interview guide used for this study (Miles and Huberman 1994).

Some contexts were notably absent in the coding and analysis of the data. In particular, there were very few instances of non-local spatial context in the data. This indicates two things: Firstly, that the entrepreneurs are not actively seeking out resources spatially tied to places outside of their local islands. Secondly, that the entrepreneurial activities for the entrepreneurs were firmly located 
in the rural island settings and do not involve being present and active in non-local spatial contexts to a large extent. 